\title{
Do risco crescente à instabilidade financeira: uma conexão entre as abordagens de Kalecki e Minsky
}

\author{
Daniel Nogueira Silva ${ }^{1}$ \\ Andreia Andrade dos Santos ${ }^{2}$
}

\begin{abstract}
Resumo: A recorrência das crises no sistema capitalista e a persistência do desemprego são algumas das questões que se colocam para serem compreendidas, especialmente pelos economistas. Entre os diversos teóricos que ajudam a entender esses problemas, Minsky fornece importantes elementos para compreender as crises financeiras, sendo a sua análise diretamente ligada com a de outros autores como Kalecki. Visando contribuir com esse debate, o objetivo deste artigo é avançar na construção de relações entre esses dois autores, analisando especialmente o "princípio do risco crescente" kaleckiano e as suas interconexões com a hipótese da instabilidade financeira de Minsky.

Palavras-Chave: Sistema Financeiro, Princípio do Risco Crescente, Hipótese da Instabilidade Financeira.

\section{From increasing risk to financial instability: a connection between Kalecki and Minsky's approaches}

\begin{abstract}
The recurrence of crises in the capitalist system and the persistence of unemployment are some of the questions that are posed to be understood, especially by economists. Among the many theorists that help to understand these problems, Minsky provides important elements for understanding financial crises, being his analysis directly linked with that of other authors as Kalecki. To contribute to this debate, the purpose of this article is to advance in building relationships between these two authors, especially analyzing the "principle of increasing risk" Kaleckian and its interconnections with the financial instability hypothesis of Minsky.
\end{abstract}

\footnotetext{
${ }^{1}$ Doutorando em Economia do Desenvolvimento pelo Programa de Pós-Graduação em Economia da Universidade Federal do Rio Grande do Sul (UFRGS). Docente da Faculdade de Ciências Econômicas da Universidade Federal do Sul e Sudeste do Pará (UNIFESSPA). E-mail: daniel.nogueira@unifesspa.edu.br

${ }^{2}$ Doutoranda em Desenvolvimento Econômico pelo Programa de Pós-Graduação em Economia na Universidade Federal da Bahia (UFBA). Assistente de Monitoramento e Avaliação do Projeto Bahia Produtiva- CAR/SDR. Email: andreiaandradeds@gmail.com
} 
Keywords: Financial System, Principle of Increasing Risk, Financial Instability Hypothesis.

Classificação JEL: E12, E32, Go1.

\section{Introdução}

A crise econômica iniciada em 2008 trouxe diversos questionamentos sobre a possibilidade dos instrumentos teóricos fornecidos pelo mainstream econômico, sintetizados por meio do "novo" consenso macroeconômico 3 , explicarem a persistência do desemprego involuntário, as bolhas especulativas e a ineficiência dos mecanismos automáticos de ajuste do mercado. Diante dessas limitações, diversas vertentes do pensamento econômico que estavam sendo negligenciadas passaram a ser recuperadas. Algumas dessas contribuições teóricas podem ajudar a construir um novo quadro de análise macroeconômica que sirva como alternativa para o pensamento dominante (RONCAGLIA, 2011).

Para Roncaglia (2011), é possível propor uma nova macroeconomia reunindo alguns desenvolvimentos teóricos que já foram esboçados e que, apesar de serem compatíveis entre si, ainda não foram articulados. Alguns dos elementos a compor esse novo quadro analítico seriam os seguintes: reconhecer os limites do mercado em garantir um equilíbrio de pleno emprego (KEYNES, 1983); ampliar o entendimento sobre a distribuição de renda, que passa a não ser determinada apenas pelas contribuições marginais dos fatores de produção no processo produtivo, em um contexto em que empresas competitivas buscam maximizar o lucro, mas principalmente por fatores sociopolíticos e econômicos (KALECKI, 1938; LABINI, 1984); e, por fim, ao analisar o sistema financeiro, acrescentar à ideia da fragilidade financeira endógena as estruturas econômicas, associada aos desequilíbrios macroeconômicos (MINSKY, 2010; STEINDL, 1952, 1990).

Esses elementos não constituem as únicas contribuições a serem incorporadas na construção de uma nova macroeconomia. A teoria marxista, os institucionalistas ${ }^{4}$, a corrente neoschumpeteriana, além de outras linhas do pensamento heterodoxo, também podem ser integradas. Apesar de existirem diferenças metodológicas e de approach teórico entre essas diversas abordagens, é possível construir nexos teóricos entre essas visões, bem como dos autores que as

\footnotetext{
3 Para uma análise das características desse "novo" consenso ver Teixeira e Missio (2011).

4 O campo de análise institucionalista possui diversas linhas de pensamento com importantes diferenças metodológicas e teóricas entre elas. Para uma melhor análise destas diferenças, ver Conceição (2002).
} 
compõem. E essa é a principal motivação deste trabalho, na medida em que tenta estabelecer uma ligação entre a Hipótese da Instabilidade Financeira de Minsky e o conceito de Kalecki do "Princípio do Risco Crescente".

Algumas relações entre esses dois teóricos já foram apontadas em diversos trabalhos. Devine (2011), ao construir um modelo macroeconômico keynesiano não convexo, aponta que há uma intersecção entre as abordagens de Minsky e Kalecki ao tratarem de períodos de grande crescimento. Em ambas as abordagens, segundo esse autor, períodos longos de alta demanda podem causar os ciclos econômicos. Lavoie (1996) também identifica fortes semelhanças entre os argumentos de Minsky e aqueles que são atribuídos aos escritos de Kalecki, especialmente os elementos que justificam uma relação positiva entre o nível de renda (taxa de investimento) e a taxa de juros. Toporowski (2012) vai apontar semelhanças na teoria monetária dos dois autores. Segundo ele, a conclusão chegada por eles aponta para os gastos capitalistas como os responsáveis por determinar a circulação de moeda na economia (moeda endógena), sendo que a política monetária e creditícia só afeta o balanço do sistema bancário.

Há também trabalhos que vão construir análises para alguns fenômenos contemporâneos partindo de modelos que relacionam as contribuições dos dois autores. Fisher e Bernardo (2014) propõem um modelo stock-flow ${ }^{5}$ para entender o funcionamento do sistema financeiro não bancário (também conhecido como shadow banking system) e seu papel nas crises financeiras, utilizando as análises de Minsky e Kalecki. Fujita e Sasaki (2011) analisam a dinâmica da distribuição de renda em um contexto de financeirização usando um modelo macroeconômico Kaleckiano e a taxonomia do regime financeiro Minskyano. Neste trabalho, eles investigam por um lado os efeitos de longo prazo de mudanças na taxa de acumulação de capital e na razão dívida-capital, e por outro, a estrutura financeira das firmas. Já Hannsgen e Young-Taft (2015) utilizam a contribuição de Minsky e Kalecky para a construção de um modelo de política fiscal.

Outros trabalhos apontam para os limites da teoria de Minsky com base na contribuição Kaleckiana. Segundo Caverzasi (2013), a crítica mais conhecida foi levantada por Lavoie e Seccareccia (2001) e depois aprofundada por outros autores como Toporowski (2008), Bellofiore e Halevi (2009), que identificam um problema de agregação na hipótese da instabilidade financeira proposta por Minsky (2010). O núcleo dessa crítica é baseado em um quadro analítico construído a por meio de Kalecki (1954), em que os gastos da firma com o investimento é também a fonte para as firmas produzirem bens de capital. Com base em uma economia fechada e simplificada, em que a diferença entre os gastos públicos e os impostos são

\footnotetext{
${ }^{5}$ Os modelos macroeconômicos de stock-flow foram popularizados por Godley e Lavoie (2012) e recentemente um survey de Caverzasi e Godin (2015) tornou mais claro as implicações políticas dentro da teoria Pós-Keynesiana.
} 
negligenciáveis e os trabalhadores consomem toda a sua renda, o nível dos lucros é determinada pelo investimento e consumo dos capitalistas e, além disso, os investimentos determinam o nível de poupança.

Nesse caso, o nível do endividamento do setor empresarial permaneceria inalterado desde que as dívidas das empresas com investimento fossem compensadas pela receita das empresas que produzem os bens de capital. De acordo com a crítica desses autores, Minsky cometeu uma "falácia de composição" quando não levou em consideração essa dinâmica e aplicou sua microanálise de investimento em um nível macro. Contudo, segundo Caverzasi (2013), assumir que ocorre uma piora na posição financeira das firmas devido a um processo de financiamento de investimentos via débito apenas implica um problema agregacional, se suposições específicas forem levadas em consideração. Apesar da relevância da crítica feita por esses autores, Caverzasi (2013), utilizando um modelo de stock-flow, aponta que as principais conclusões da teoria de Minsky sobre a fragilidade financeira ainda são válidas para uma análise agregada.

Visando contribuir para a construção de inter-relações entre as contribuições de Kalecki e Minsky, o objetivo do artigo é apresentar a relação entre o princípio do risco crescente kaleckiano e a hipótese de fragilidade financeira proposta por Minsky. Apesar de vários trabalhos assumirem essa relação (MOTT, 2004; TIMOIGNE, 2006; TOPOROWSKI, 2008), a mesma tem sido pouco aprofundada. Nesse sentido, o presente artigo discutirá, em um primeiro momento, a forma como o princípio kaleckiano do risco crescente ajuda a entender os limites impostos ao investimento. Através desse princípio é possível relacionar a dinâmica das economias capitalistas com o enfraquecimento financeiro endógeno ao sistema econômico, questão esta tratada por Minsky por meio da Hipótese da Instabilidade Financeira (HIF).

O trabalho está estruturado da seguinte forma: além desta introdução e da conclusão, em que são sintetizadas as principais ideias deste trabalho, na segunda parte é apresentada a teoria do investimento de Kalecki e sua crítica a algumas teorias que tentam explicar os determinantes do investimento, incluindo a abordagem proposta por Keynes. Com base nessa argumentação, na terceira parte é discutido o princípio kaleckiano do risco crescente e suas implicações para a decisão do investimento. O objetivo é apresentar os argumentos teóricos fornecidos por Kalecki que relacionam o nível de risco assumido pelas empresas com a proporção de capital próprio. Uma das implicações dessa relação é um maior destaque dado ao papel que os lucros desempenham na dinâmica das economias capitalistas, já que a realização dos lucros tem a capacidade de reduzir os riscos empresariais. Partindo dessa análise, e com base na Hipótese da Instabilidade Financeira de Minsky, é apresentada de que maneira a centralidade dos lucros na 
teoria de Kalecki torna-se fundamental para compreender as estruturas financeiras das economias capitalistas, objetivo da parte três.

\section{Kalecki e a teoria do investimento}

O Princípio do Risco Crescente desenvolvido por Kalecki (1937b) surgiu como um esforço teórico seu em construir uma explicação alternativa à teoria clássica dos limitantes do tamanho das firmas. Os principais argumentos em sua época relacionavam tais limitações com as condições de mercado ou as condições internas da própria empresa. Ao analisar esses fatores que determinam o tamanho de uma firma, Kalecki (1958) critica dois desses argumentos: os efeitos das deseconomias de escala e as limitações do mercado.

Os problemas ligados à escala de produção, segundo Kalecki (1937b), são insuficientes para explicar os limites no tamanho da firma. Apesar de existirem fatores, como a capacidade técnica das máquinas e os problemas de gestão, que definem um nível de escala ótimo da fábrica, isto não impede que a mesma empresa construa outras fábricas, ampliando a sua produção. Já os problemas da administração que ocorrem à medida que o tamanho da planta é ampliado podem ser resolvidos por intermédio da descentralização e outras formas de gerenciamento $^{6}$. A crítica fundamental de Kalecki (1937b) para o segundo argumento, as limitações do mercado, é a ausência de um tratamento explícito para a concorrência propriamente dita. A existência da competição imperfeita, apesar de mais realista por levar em consideração as limitações do mercado, não consegue explicar a existência em um mesmo ramo de negócio de firmas grandes e pequenas. Haveria outros fatores que limitam o tamanho da firma e que não podem ser entendidos apenas com esses dois argumentos.

Para Kalecki (1954) a quantidade de capital que a firma possui é um fator de importância decisiva na limitação do tamanho de uma firma. Isto não significa que todo investimento feito pela empresa provém apenas dos recursos que a firma possui, já que o mercado financeiro financia boa parte desses investimentos. Contudo, mesmo quando a empresa busca crédito, o acesso ao mercado de capitais é em grande parte determinada pelo volume do capital dessa empresa. O tamanho da firma parece, dessa forma, limitado pelo volume de capital da empresa. Com isso, a decisão de expandir da firma dependeria de sua acumulação de capital por meio dos lucros correntes. Contudo, existem outros fatores que também afetam a expansão dos negócios, e que estão relacionados à decisão de investir do empresário.

\footnotetext{
${ }^{6}$ Nelson (2008) constrói um importante nexo teórico em que associa o desenvolvimento da organização industrial com as mudanças tecnológicas, através do processo de mudança institucional.
} 
A decisão de investimento passa em primeiro lugar pela observação das condições do mercado, como preços das matérias-primas e do produto em questão. Além dessas informações, o empresário tem uma vaga ideia de como se comportarão os preços e os custos futuros. Com base nessas informações, tanto do presente como do futuro, ele planeja seu investimento, definindo o montante de capital $(k)$ e o método de produção a ser aplicado, com o objetivo de auferir uma série de retornos futuros $\left(q_{1}, q_{2}, \ldots, q_{n}\right)$, durante o período de funcionamento da fábrica. $O$ nível de eficiência do investimento é medido pela taxa $\varepsilon$, em que a série de retornos deve ser descontada a fim de obter o montante investido ( $k$ ). Assim, para um montante de capital $(k)$, o empresário decide qual método de produção maximizará a eficiência do investimento, ou em outras palavras, qual montante de lucro ele deseja alcançar dado o capital investido.

Ao tratar do conceito de eficiência do investimento, Kalecki (1937b) faz uma conexão com a Teoria Geral de Keynes (1983), já que esse conceito tem o mesmo sentido da eficiência marginal do capital (EMC). O problema apontado por Kalecki (1937b) é que na teoria do investimento de Keynes, apesar de considerar os riscos assumidos pelo emprestador e pelo tomador, nada é colocado sobre o risco associado ao nível do capital próprio aplicado.

Para Keynes (1983), a EMC é a relação entre a renda esperada de um bem de capital e o custo de reposição, sendo definida, portanto, em termos de expectativa de renda e pelo preço da oferta corrente do bem de capital. Ou seja, ao fazer o investimento, o indivíduo espera receber um fluxo de rendas futuras pela venda do seu produto, chamada de renda esperada. Por outro lado, tem-se o preço de oferta do bem de capital que é o custo de reposição, isto é, o valor que o fabricante deverá pagar para repor uma nova unidade suplementar desse capital. $\mathrm{O}$ argumento de Keynes (1983) é que o investimento ocorre até o ponto em que a eficiência marginal do capital, ou a taxa potencial de retorno sobre o investimento, seja igual à taxa de juros, podendo ser alterada à medida que as expectativas mudam. Além disso, ao assumir o investimento, dois riscos afetam o volume total investido: o risco do tomador de empréstimo e o risco do emprestador, e eles estão diretamente relacionados com as expectativas desses agentes. É nesse ponto que, segundo Kalecki (1937a), é necessário ampliar a análise de Keynes sobre os determinantes do investimento.

Avançando em sua análise, Kalecki (1937b) apresenta o significado da decisão do investimento por unidade de tempo. Durante o período $\Delta$ t o empresário poupa certo montante $(s)$ de sua renda. Nesse caso, ele pode investir o novo montante acumulado sem reduzir a sua segurança ou aumentar a sua iliquidez. Ele pode ampliar seus investimentos, considerando que a razão de sua dívida líquida em relação ao seu próprio capital é de $\delta$, no nível de $s(I+d) \Delta t$. Caso ocorram mudanças positivas na situação econômica que ampliem a rentabilidade líquida 
marginal, o empresário é levado a ampliar o seu investimento em (c). Como consequência, o investimento planejado durante o período $\Delta$ t é de $s(I+d) \Delta t+c$ e assim a taxa de investimento do período é:

$$
d=s(I+d)+c / \Delta t
$$

Essa equação significa que a taxa de decisões de investimento de um único empresário depende de sua acumulação de capital e da velocidade de mudança da rentabilidade líquida marginal. Kalecki (1983) aprofunda a sua compreensão sobre os fatores que induzem os empresários a reverem seus investimentos. A primeira é a acumulação bruta de capital pelas firmas, que além de expandir os limites impostos pelas restrições do mercado de capital, também reduzem o "risco crescente" enfrentado pelas firmas. Assim, a taxa de decisões de investir em capital (d) é uma função crescente do total da poupança bruta (s). Outro aspecto que induz os empresários a ampliarem seus investimentos são as modificações nos lucros e no estoque de capital fixo.

Um aumento dos lucros por unidade de tempo no período de aplicação do investimento torna atraente outros projetos que anteriormente não eram considerados lucrativos, o que permite que os planos de investimento sejam ampliados no decorrer do período. Já o aumento no volume de capital, na situação em que os lucros $(P)$ se mantenham constantes, significa uma redução do montante de lucros. Em síntese, a taxa de decisão do investimento $(D)$, como uma primeira aproximação, é uma função crescente da poupança bruta $(S)$ e da variação dos lucros ao longo do tempo $(\Delta P / \Delta t)$, e uma função decrescente da taxa de modificação do estoque de capital em equipamento, $(\Delta P / \Delta t)$.

Em relação ao primeiro fator, quanto maior for o nível de atividade econômica, maior será a poupança bruta das empresas que tende a ser investida, aumentando o capital empresarial, além de ampliar a possibilidade de a firma adquirir empréstimos. Kalecki (1983) leva em consideração que a poupança interna dos capitalistas $\left(e S_{t}\right)$ é parte significativa da poupança total da sociedade $\left(a S_{t}\right)$, simplificando então o modelo, ao utilizar essa última.

A variação dos lucros por unidade de tempo $(\Delta P / \Delta t)$ é o segundo fator que afeta a decisão de efetuar o investimento. Mesmo dispondo da poupança necessária a investir, os capitalistas observam a variação no montante de lucro para decidirem se aplicarão os seus recursos, ou os de terceiros, para a ampliação da atividade produtiva. Assim, as decisões de investimento variam no mesmo sentido das variações no montante de lucro. Considerando que o montante de lucro também pode ser expresso pela relação entre lucro $(P)$ e pelo estoque de capital fixo $(K)$, isto é, $(P / K)$, pode-se concluir que o investimento é influenciado negativamente pelo acréscimo no estoque de capital $(\Delta K / \Delta t)$. 
Soma-se a essas variáveis uma constante $d$, significando as alterações autônomas que ocorrem no longo prazo, incluindo as inovações tecnológicas. Com isso, a decisão de investimento pode ser representada da seguinte forma:

$$
D_{t+Z}=a S_{t}+b \Delta P / \Delta t-c \Delta K / \Delta t+d
$$

Os coeficientes $a, b$ e $c$ expressam a intensidade com que o investimento $D$ no período $t+z$ reage em função da poupança bruta no período anterior, bem como as variações no lucro e no estoque de capital no momento que antecede o período $t+z$.

\section{O princípio do risco crescente}

As análises sobre o investimento, em geral, não consideram como o volume do capital próprio do empresário afeta a taxa de risco do investimento. Kalecki (1937b), ao contrário, aponta alguns motivos para que o risco marginal aumente à medida que se amplia o capital investido, o que ele chamou de "princípio do risco crescente". Um dos riscos enfrentado pelo empresário é o da perda do capital investido. Se, por exemplo, o empresário constrói uma fábrica, ele corre certo risco de o negócio não ser lucrativo, e se houver essas perdas, ela será mais significativa quanto maior for a proporção de sua riqueza nesse investimento. Além disso, ao utilizar as suas reservas de recursos na compra de máquinas, equipamentos, ou qualquer outro investimento físico, ele perde a liquidez do seu capital, tendo que buscar recursos no sistema financeiro caso necessite de novos fundos.

A necessidade de empréstimo transfere ao credor parte da incerteza que pertencia apenas à empresa. Como consequência, as taxas de juros são elevadas com o objetivo de compensar a carga de risco crescente que o emprestador assume. Até mesmo o acesso da firma ao mercado de capitais, uma forma de ampliar o seu investimento com o uso de capital externo, é limitado pelo volume do capital próprio da empresa (KALECKI, 1983). O risco crescente, que decorre do aumento do capital investido, leva a necessidade de rever a teoria de Keynes dos gastos para investimento. É preciso acrescentar o prêmio do risco marginal à taxa de juros para explicar os fatores que determinam os limites do investimento. 
Figura 1 - Eficiência Marginal do Investimento e Nível de Capital.

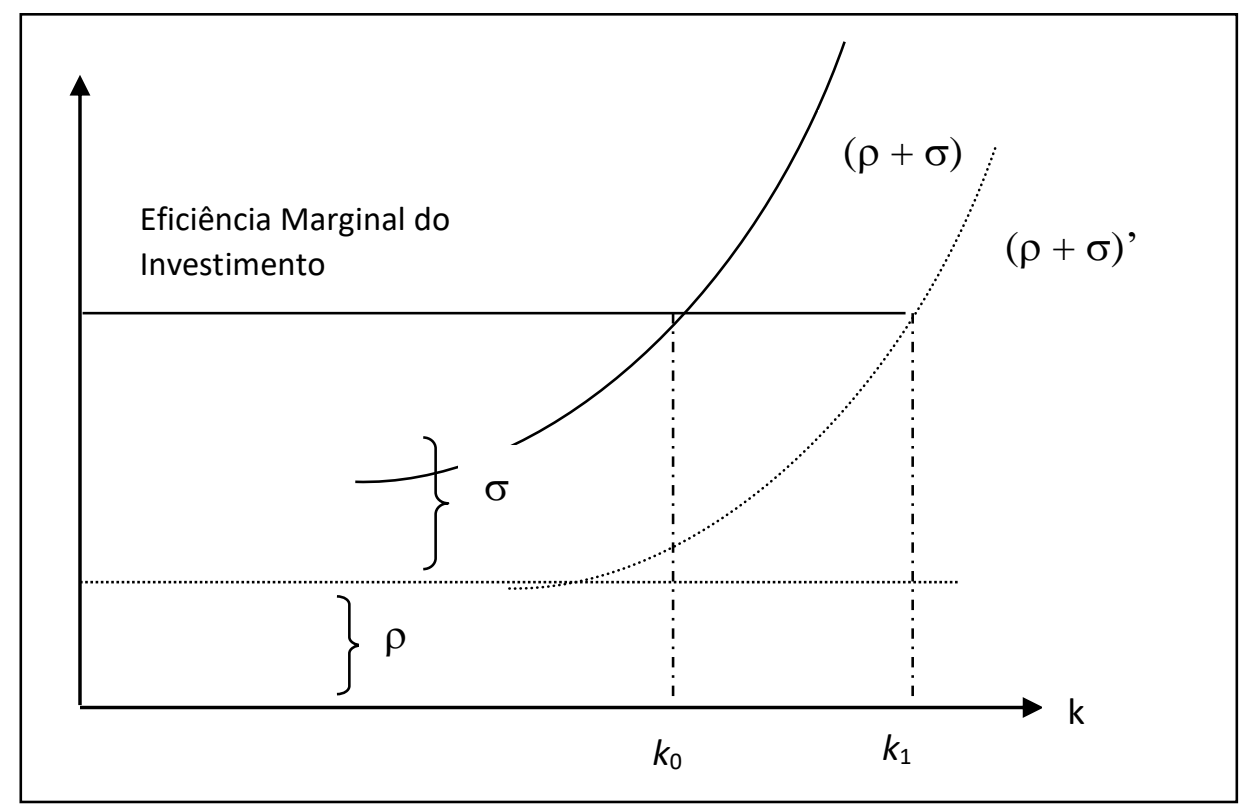

Fonte: Adaptado de Kalecki 1937b.

Baseado na Figura 1 é possível tornar mais claro esses argumentos. Nele o volume de um capital investido $k$ é determinado pelo nível em que a eficiência marginal do investimento é igual à taxa de juros $(r)$ somada à provisão para o risco $(s)$. A curva $(r+s)$ possui uma inclinação positiva, já que ela cresce à medida que se amplia o capital. Considerando que os juros tendem a ser constantes no decorrer do tempo, é a provisão do risco que fornece o formato positivo da curva.

$\mathrm{O}$ ponto de intersecção com a curva de eficiência marginal determina o volume do investimento $\left(k_{\mathrm{o}}\right)$ e esse ponto existe mesmo que não haja deseconomias de escala ou que seja assumida a concorrência perfeita (KALECKI, 1937). É possível, dessa forma, explicar a presença de várias empresas de tamanhos diferentes em um determinado ramo de produção, pois não é o tamanho da firma que define o investimento, mas a quantidade de capital próprio. Dessa maneira, segundo Kalecki, o acesso ao crédito é um limitante e não condicionante do investimento, apesar de incluir a poupança linearmente na equação das decisões de investir. Assim, quanto menor o capital próprio, mais elevado se encontra a curva $(r+s)$ e, como consequência, menor é o capital $\left(k_{\mathrm{o}}\right)$ investido. Assim, Kalecki (1983) argumenta que a "democracia dos negócios" é uma falácia, já que o capital próprio é relevante pra que o investimento desejado se realize. 
Com base na Figura 1 também é possível entender o que ocorre quando a taxa de juros cai. Nessa situação, a curva $(r+s)$ vai para baixo $(r+s)$ ', e o ponto de intersecção com a eficiência marginal vai para a direita. Não ocorrem alterações no método de produção aplicado pelo empresário em sua planta, entretanto a taxa de investimento aumenta $\left(k_{1}\right)$. Mesmo se for negligenciada a competição imperfeita, se introduzirmos o princípio kaleckiano do risco crescente, a queda da taxa de juros não tem imediato efeito no método de produção aplicado nos planos do empresário. Fica claro que não é apenas a taxa de juros que determina o nível do investimento, já que ela tende a ser estável ao longo do ciclo. É o prêmio do risco que precisa ser considerado.

Figura 2 - Relação da Taxa de Juros e Endividamento.

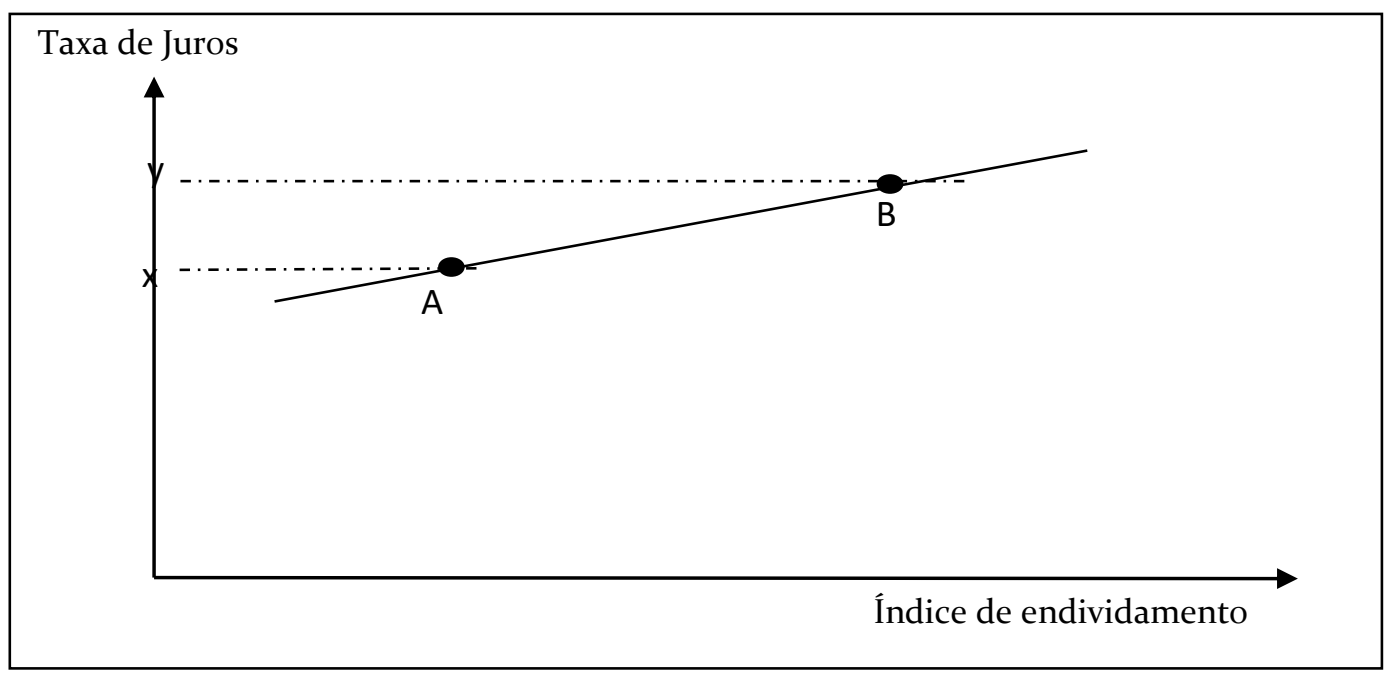

Fonte: Adaptado de Lavoie (1996).

Lavoie (1996) apresenta uma forma alternativa de entender o "princípio do risco crescente" de Kalecki utilizando a relação entre juros sobre os empréstimos e um índice de endividamento7 (Figura 2), proposto por Hewitson (1995). Considerando A e B como sendo duas empresas com níveis diferentes de alavancagem, as empresas com níveis mais altos de endividamento terão o seu

\footnotetext{
${ }^{7}$ Esse índice é definido como a razão entre a dívida e o patrimônio líquido, mas Lavoie (1996) considera que podem ser utilizados outros indicadores de endividamento.
} 
risco também elevado, o que é refletido em taxas de juros mais altas ${ }^{8}, \mathrm{x}$ e $\mathrm{y}$, respectivamente. Essa relação só é possível de ser construída caso seja considerado que todo o capital aplicado surge do endividamento da firma. Uma suposição plausível, apesar de haver situações em que a empresa pode utilizar o capital próprio para ampliar seus investimentos, como ressalta o Kalecki (1937b). Segundo Lavoie (1996), a análise pode ser feita tanto para tratar duas empresas em um mesmo período de tempo como em uma série temporal. Os pontos A e B passam a serem considerados momentos diferentes ao longo do tempo. Nesse caso, pode-se interpretar como se a empresa, ou a economia, passasse do ponto A para o B, no momento em que é ampliado o endividamento.

O Princípio do Risco Crescente foi adotado por diversos economistas, entre os quais Minsky, que o utilizou na construção da sua Hipótese da Instabilidade Financeira. Com base nesse princípio e na teoria do investimento de Kalecki, é possível construir uma conexão entre os problemas da economia capitalista com as questões ligadas ao acesso à riqueza e à preferência pela liquidez, o que combina precisamente com o objetivo de Minsky de introduzir, dentro da análise keynesiana, a decisão dos investimentos a questão dos passivos.

Em Minsky (2011), quando a economia cresce é razoável que o nível de alavancagem aceitável suba, e como consequência, as empresas terão mais riscos e mais posições alavancadas. Dessa maneira, é possível perceber que a hipótese da instabilidade financeira desenvolvida em Minsky (2010) também pode ser derivada da análise de Kalecki. Além disso, em estudos sobre investimento, a ideia kaleckiana da relação positiva entre o nível do prêmio de risco e o nível de capital empresarial também pode ser conduzida com a utilização de lucros atuais ou fluxo de caixa, com os níveis de dívida (ou a razão entre dívida e produto), entre outras medidas de acesso das empresas à liquidez. A Hipótese da Instabilidade Financeira (HIF) de Hyman Minsky traz as implicações do princípio do risco crescente, tanto por meio da análise dos padrões cíclicos e seculares quanto pelo efeito do financiamento dos investimentos, produzindo uma interpretação que amplia as teorias de Keynes e de Kalecki (MOTT, 2004).

\section{Lucros e a hipótese da instabilidade financeira}

Segundo o princípio kaleckiano do risco crescente, à medida que o montante de capital investido na produção aumenta, ampliam-se os riscos assumidos pelo empresário para um dado investimento. Haveria duas razões para o risco marginal

\footnotetext{
${ }^{8}$ Esse tipo de prática é comum de ser feita pelas empresas de rating, como Standard Poors ou Moody. As empresas que são consideradas como sendo "mais arriscadas" só conseguem empréstimos pagando níveis mais altos de juros (LAVOIE, 1996).
} 
aumentar com o montante investido. A primeira é o fato de que quanto maior o investimento empresarial maior também será a riqueza do empresário que ficará em risco no caso de insucesso nos negócios. A segunda razão está relacionada com o problema de "iliquidez" associado a todo tipo de investimento. Segundo Kalecki (1937b), a venda súbita de uma empresa, na maioria das vezes, está relacionada a perdas. Nesse caso, um montante de capital investido em máquinas e equipamentos, por exemplo, pode ser considerado como um ativo plenamente ilíquido no caso de uma necessidade repentina de capital.

Nas situações em que o empresário toma empréstimos para financiar seus investimentos, o risco não deixa de existir, ele apenas é transferido para os credores, sendo refletido nas taxas de juros aplicadas. Para Kalecki (1937b), uma das formas para reduzir os riscos empresariais relacionados à ampliação do montante de capital investido é por meio da realização dos lucros esperados. Quando as expectativas em relação às receitas se concretizam ou são superadas, o risco é reduzido, o que permite a empresa ampliar o seu investimento. Assim, é fundamental entender a teoria kaleckiana dos lucros para identificar os mecanismos que possibilitam uma redução dos riscos ligados ao investimento.

Apesar de não ser o ponto central no seu trabalho de 1937b, a teoria de Kalecki sobre os lucros possibilita compreender o comportamento ao longo do tempo das economias capitalistas que apresentam estruturas financeiras complexas. A ênfase kaleckiana sobre os lucros permite integrar uma teoria referente às estruturas financeiras com a dinâmica das economias capitalistas, já que, em determinadas circunstâncias, os lucros são a base que sustenta toda a estrutura financeira das firmas (RONCAGLIA, 2013).

Segundo Fazari, Ferri e Greenberg (2008), a conexão entre as condições da economia agregada e os lucros, presente nos trabalhos de Kalecki, também foi incorporada explicitamente nos últimos trabalhos de Hyman Minsky, apesar de ter sido, em alguns momentos, atribuído a outros autores (TOPOROWSKY, 2012). Para Minsky (2010), o investimento é financiado por meio dos fluxos de caixa gerados internamente e das dívidas assumidas. Segundo Toporowsky (2008), depois de ter finalizado seus estudos sobre Keynes na metade da década de 1970, Minsky passou a adotar a teoria dos lucros de Kalecki, passando a considerar que a lucratividade da firma é determinada pelos gastos capitalistas, principalmente com investimentos. Essa teoria possibilitou que Minsky tornasse a fragilidade financeira endógena no sistema. Nesse caso, o fluxo de caixa do setor empresarial é reduzido à medida que o investimento cai após um período de boom. Com o fluxo de caixa 
reduzido, a resolução dos compromissos financeiros pelas empresas se tornou mais difícil, o que leva a uma crise de sobre-endividamento9.

Aqueles que ainda não estão familiarizados com as contribuições de Minsky tendem a reduzir da sua análise exclusivamente a teoria da fragilidade financeira fornecendo, por exemplo, uma única explicação financeira para recente crise mundial, iniciada a partir de 2008. Todavia, na teoria de Minsky, bem como em eventos recentes, a fragilidade financeira interage com crescentes desigualdades na distribuição de renda, o que implica uma forte relação entre o lado real e financeiro das economias.

Ao analisar as teorias contemporâneas que tentam explicar a crise financeira de 1929, Minsky (2013) verificou que é dado um grande peso aos níveis de endividamento assumidos no período prévio à quebra da Bolsa de Nova York. Entretanto, em 1933 as firmas estavam bem mais endividadas do que em 1929. Sendo assim, para esse autor, o principal problema causador da Crise de 29 não foram os níveis de endividamento das empresas, e sim a queda nos lucros.

Contabilmente, uma forma de mensurar o grau de endividamento de uma empresa é por meio da relação entre o passivo $(t)$, que compreende os seus compromissos de pagamentos assumidos com terceiros, e seus ativos $(a)$, que são as fontes de recursos originadas pelo capital próprio da empresa. Utilizando essa medida de endividamento $(t / a)$, o aumento do peso da dívida pode ser entendido tanto observando o numerador quanto o denominador. Se os lucros esperados forem realizados, há uma tendência de que a carga de endividamento se mantenha constante, já que o denominador é reduzido.

O pleno funcionamento de economias que apresentam estruturas financeiras complexas depende que os compromissos assumidos sejam validados pelo fluxo de rendimento. Os lucros da empresa devem ser suficientes para saldar as dívidas de cada período. As dívidas e os compromissos financeiros são como uma pirâmide invertida. Na base dela estão os lucros, e são eles que sustentam a maior parte dessa vasta e complicada rede de compromissos ${ }^{10}$. A equação de lucros de Kalecki permite fazer as conexões necessárias entre o funcionamento da economia e a sua estrutura financeira.

Kalecki's emphasis is upon profits being determined by social conditions, by the way demand is determined. The Kaleckian profit equation opens up the way to relate the

\footnotetext{
${ }^{9}$ Apesar de Minsky adotar a teoria dos lucros de Kalecki, até nesse momento, ele ignorava os aspectos monetários e creditícios dessa teoria (TOPOROWSKI, 2008).

${ }^{10}$ Esse mesmo raciocínio pode ser ampliado para analisar as dívidas das famílias e dos governos, relacionando-as com a renda e os tributos, respectivamente.
} 
performance of the economy in terms of employment and profits to the liability structure of businesses and households (MINSKY, 2013, p.98).

Na ótica de Kalecki, o problema central das economias capitalistas é de "realização da produção". O seu objetivo ao levantar esse problema era demonstrar que são os gastos capitalistas que determinam em última instância o volume dos lucros. Dessa forma, dada uma determinada capacidade produtiva da economia e de distribuição de renda, são a acumulação de capital (o investimento) e o consumo dos capitalistas as variáveis fundamentais para determinar os lucros, os salários e a renda nacional. Além disso, essa análise é fundamental para uma abordagem que deseja analisar como as crises capitalistas são geradas endogenamente. Dessa forma, se os lucros puderem ser mantidos, seja por intermédio do investimento privado, seja pelo déficit público, as crises podem ser suavizadas. A ênfase sobre os lucros leva à análise das estruturas financeiras e dos fluxos de caixa que vão sustentar toda essa estrutura.

Para chegar à equação completa dos lucros, Kalecki (1954) vai considerar uma economia com governo, com o comércio exterior, na qual os trabalhadores poupam uma parte dos seus salários. A equação (1) completa dos lucros pode ser representada da seguinte forma:

$$
L=C c+I+\Delta X+\Delta G+S w
$$

Em que L são os lucros, $C c$ é o consumo dos capitalistas, $I$ é o investimento, $\Delta X$ o saldos das exportações, $\Delta G$ o déficit orçamentário do governo e $S w$ a poupança dos trabalhadores. Para chegar a essa equação, Kalecki parte de um modelo simplificado em que o lucro total é igual à soma do investimento com o consumo dos capitalistas. Contudo, não se pode afirmar que são os lucros dos capitalistas que determinam seus gastos. Para chegar à equação completa dos lucros, Kalecki vai suspender as hipóteses simplificadoras que resultam na equação simplificada dos lucros e passa a considerar as demais variáveis.

Analisando os três últimos componentes da equação completa dos lucros (1) pode se perceber que, primeiro, quanto maior a poupança dos trabalhadores $(S w)$, menor será o lucro dos capitalistas; e em segundo, o aumento das exportações líquidas $(\Delta X)$ necessariamente elevará os lucros totais. Por fim, um déficit orçamentário do governo $(\Delta G)$ representa uma elevação no volume dos lucros. Com base nessa equação, os lucros são determinados pela forma como a produção é dividida entre os diversos componentes da demanda.

A instabilidade do capitalismo está diretamente associada com as flutuações nos lucros. Por isso a teoria de como os lucros são realizados, presente também nos trabalhos de Marx, Keynes, Levy, torna-se tão importante. No trabalho maduro de 
Minsky, o mecanismo chave que leva a erosão das estruturas financeiras é a relação positiva entre gastos com investimento e o lucro das empresas, que ele incorporou a partir do trabalho de Kalecki (1954). Segundo Tapia (2015), a equação básica dos lucros presente no trabalho de Minsky (2010) seguiu de perto o olhar de Kalecki sobre essa variável, com a diferença de que Minsky adicionou a suposição de que os capitalistas não consomem. Como consequência, chegou à conclusão de que lucros seriam iguais ao investimento, dando a ele um importante insight para entender como as economias capitalistas funcionam.

Segundo Minsky (2010), quando os gastos com investimento são fortes, a demanda agregada e, portanto, os lucros agregados das empresas, também são fortes, de modo que os fluxos de caixa das empresas excedem as expectativas, provando ser mais do que suficiente para atender aos compromissos de caixa existentes. Assim, a lição é aprendida que a cautela anterior era excessiva, e portanto, a estrada é aberta para uma mudança para finanças mais frágeis. Para entender os fatores que levam à fragilidade dessas estruturas financeiras, Minsky (2010) analisou a relação entre o fluxo de caixa das firmas - receita, balanços financeiros e carteiras de títulos - com seus compromissos financeiros, classificando as firmas, a partir dessa análise, em três posições: Hedge, Especulativa e Ponzi.

A posição Hedge é caracterizada quando em cada período a diferença entre as receitas e despesas previstas é positiva, isto é, quando os fluxos de caixa são suficientes para cumprir com as obrigações assumidas pela firma. Em segundo lugar, temos a posição Especulativa, que ocorre sempre que o fluxo de recebimentos esperados em um determinado período for inferior aos desembolsos esperados, de modo que o agente sabe que o refinanciamento de curto prazo será necessário em algum momento. Nessa situação, em geral, só é possível pagar os serviços das dívidas que foram assumidas. Por fim, temos as posições ultraespeculativas, também chamadas de Ponzi. Tais posições são caracterizadas por receitas previstas sistematicamente inferiores aos gastos esperados para um período relativamente longo. A impossibilidade de cumprir as obrigações leva à necessidade de renegociar os compromissos assumidos. Nas duas últimas situações, as firmas são mais sensíveis às mudanças nas taxas de juros, já que elas são dependentes das condições oferecidas pelo mercado financeiro para que possam honrar as suas dívidas.

Ao enfatizar a forma como é feito o financiamento do investimento, Minsky também reproduz as ideias que já estavam presentes em Kalecki (RONCAGLIA, 2013). Tanto o financiamento interno quanto o financiamento externo dependem da realização dos lucros para terem seus compromissos financeiros cumpridos. Os fundos internos vêm da poupança interna acumulada, que está diretamente relacionada aos lucros passados. Uma taxa positiva de crescimento sustentado gera 
maiores lucros, que levam à melhora das expectativas e uma reavaliação positiva dos riscos. Entretanto, à medida que a economia vai crescendo, as avaliações de risco tornam-se progressivamente mais otimistas, como consequência, posições tidas como especulativas passam a ser avaliadas como sendo cobertas. Assim, a fragilidade financeira cresce tanto para empresas financeiras quanto para as que não são financeiras, podendo ser ampliada para as famílias e o governo.

Ao analisar os fatores que suscitaram o surgimento das bolhas de ativos na Califórnia, no Japão e na Coreia do Sul em meados da década de 1990, Dimsky (1998) constrói um quadro estilizado (Figura 3) de como se desdobra uma crise minskyana no decorrer do tempo. Apesar de enfatizar o papel de uma bolha de ativos sobre a flutuação econômica, é possível utilizar os mesmos esquemas para compreender como se desenvolvem os estágios de um ciclo minskyano geral.

As economias capitalistas com setores financeiros desenvolvidos seguem uma sequência cíclica que envolve quatro estágios (MINSKY, 2010 e 1964). A relação entre os preços de produção dos ativos de capital $\left(P^{1}\right)$ e o preço do mercado de ações $\left(P^{K}\right)$, chamado por Minsky (2010) de modelo de "dois preços", é útil para entender como o sistema financeiro passa de uma condição de "equilíbrio" para um colapso. Mas outros elementos, como a relação dívida/renda e a utilização da capacidade, também sinalizam o processo de fragilização financeira que leva às crises. 
Figura 3 - Crise na Perspectiva de Minsky.

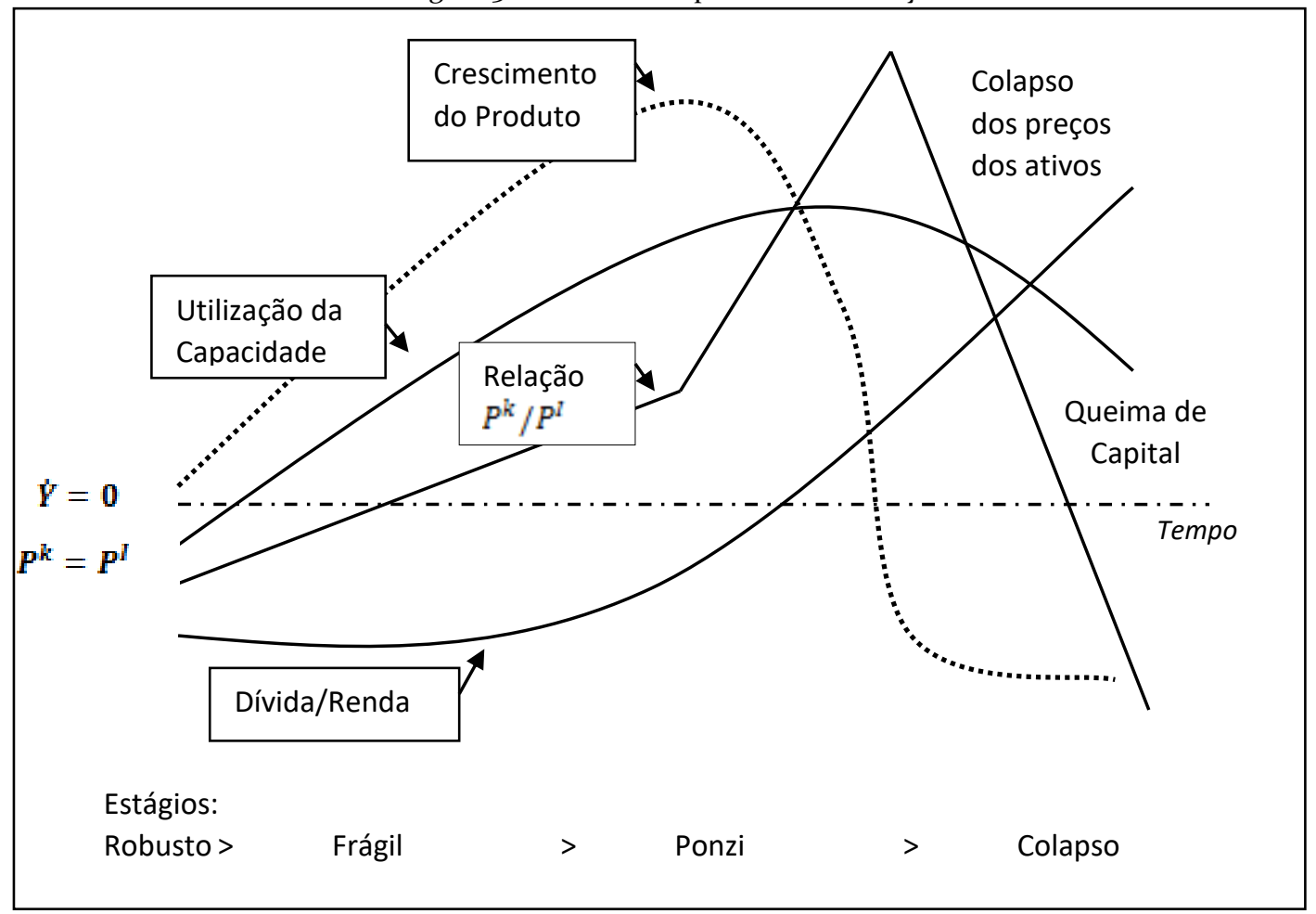

Fonte: Adaptado de Dimsky (1998).

No estágio I, em que ocorre um crescimento financeiramente robusto, $p^{k}$ é igual a $p^{1}$. Nessa fase, há um rápido crescimento do produto, mas ainda existe muita capacidade ociosa. Os ativos das empresas aumentam pouco $(\Delta A)$, enquanto o passivo permanece fixo $(\Delta P)$, o que mantém a relação ativo/passivo ainda baixa $(\Delta A / \Delta P)$. A relação dívida/renda também é baixa. No estágio II aumenta-se o uso da capacidade, enquanto o crescimento do produto se mantém acelerado. Nesse momento, cresce a relação ativo/passivo $(\Delta A>\Delta P)$ e também ocorre um aumento, mas moderado, nos preços de produção dos ativos de capital e no mercado de ações $\left(\Delta P^{1}=\Delta P^{k}\right)$. O crescimento nessa fase é financeiramente frágil, mas somente no estágio III é que ocorre um crescimento Ponzi.

O crescimento do produto no estágio III começa a desacelerar e, em um segundo momento nessa mesma fase, passa a contrair. Com isso, há uma reversão no uso da capacidade, ampliando os níveis de ociosidade. As relações entre ativo/passivo e dívida/renda tornam-se altas e a variação nos preços do mercado de ações passa a ser maior do que no mercado de produtos $\left(\Delta P^{1}<\Delta P^{k}\right)$. Por fim, a 
economia entra em colapso, com a forte contração do produto e a elevada capacidade ociosa. Nesse momento há uma explosão da dívida e um esgotamento do mercado acionário.

\section{Conclusão}

O investimento é fundamental para garantir o crescimento da economia, mas a decisão de investir exige que o empresário assuma riscos, já que as suas decisões são movidas por expectativas que nem sempre são concretizadas. Além de afetar o nível da produção e a capacidade produtiva, os investimentos afetam também as estruturas financeiras, já que os bens de capital, para serem financiados, necessitam de recursos que na maioria das vezes a empresa não dispõe. Um dos motivos que fazem as economias capitalistas oscilarem é o fato que as suas práticas e seus compromissos financeiros variam no decorrer do tempo, tendo como base as expectativas de ganhos que a empresa possui. Apesar de estar ausente na análise de Kalecki, de forma explícita, o elemento da incerteza que acompanha a decisão de investimento" ${ }^{\text {, }}$, seus insights teóricos possibilitam ampliar o debate sobre os determinantes do investimento. Além disso, colabora para um melhor entendimento do funcionamento das economias contemporâneas.

O princípio kaleckiano do risco crescente impõe mais um custo, que até então não era considerado nas teorias sobre os determinantes do investimento. A quantidade de capital próprio é um limite imposto ao empresário para que ele invista. Sendo assim, o empresário tem duas formas de ampliar o seu capital: a primeira é por intermédio dos empréstimos que ele pode tomar, mas que também depende da quantidade de capital que o capitalista possui. A outra forma é por meio da realização dos lucros, que ampliam a sua acumulação bruta de capital.

Segundo esse princípio, quanto maior for o investimento, dado o capital próprio da firma, maior também serão os riscos enfrentados tanto pela firma que utiliza as fontes externas de financiamento quanto pelos agentes que lhes fornecem o crédito. Isto acontece porque um maior investimento exige uma maior parcela da receita originada em capitais que são financiados externamente, impondo ao investidor o custo dos juros do financiamento. Dessa forma, quanto maior o investimento, maior também será o custo para financiá-lo, o que expõe à firma tomadora de empréstimo um risco crescente de se tornar incapaz de saldar seus compromissos financeiros, na situação em que as receitas realizadas sejam menores do que as esperadas. Contudo, mesmo que as receitas sejam alcançadas e a firma obtenha lucros, isso não a torna protegida de riscos.

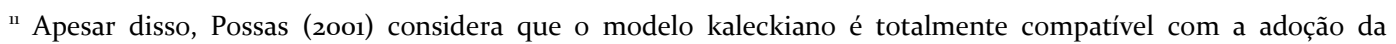
hipótese das expectativas adaptativas.
} 
Como argumentado por Minsky (2010), à medida que os lucros vão se realizando, há uma tendência das firmas assumirem posições cada vez mais arriscadas, já que suas expectativas são ampliadas pelos bons resultados. A realização dos lucros passa a ter uma função contraditória. Por ampliar a formação de capital bruto da firma há uma redução na dependência de recursos externos, que são mais sensíveis às mudanças no mercado financeiro, ao mesmo tempo em que aumenta as possibilidades de acesso ao mercado de crédito. Como consequência, o aumento dos lucros leva as empresas a reverem as suas posições e, assim, arriscarem mais recursos em novos investimentos, em geral, adquiridos via sistema financeiro. O período de prosperidade termina por ampliar a instabilidade do sistema econômico e impõe a necessidade de as autoridades governamentais criarem mecanismos que busquem tornar o capitalismo mais estável e menos suscetível a grandes oscilações.

Referências

BELLOFIORE, R.; J. HALEVI. A Minsky Moment? The Subprime Crisis and the New Capitalism. In: C. GNOS, C.; ROCHON, L.P. (Eds.), Credit, Money and Macroeconomic Policy: A Post-Keynesian Approach. Cheltenham: Edward Elgar. 2009.

CAVERZASI, E. The Missing Macro Link. New York: The Levy Economic Institute, Feb. 2013. (Working Paper, n. 753).

CAVERZASI, E.; GODIN. A. Post-Keynesian Stock-flow Consistent Modelling: A Survey. Cambridge Journal of Economics, v. 39, n. 1, p. 157-187, 2015. DOI: https://doi.org/10.1093/cje/beuo21

CONCEIÇÃO, O. O conceito de instituição nas modernas abordagens institucionalistas. Revista de Economia Contemporânea. Rio de Janeiro, v. 6, n. 2, p. 119-146, jul./dez. 2002.

DEVINE, J. G. The great moderation and "falling off a cliff": Neo-Kaldorian dynamics. Journal of Economic Behavior \& Organization. Tennessee, v. 78, n. 3, p. 366-373, mai. 2011.

DYMSKI, G. "Economia de bolha" e crise financeira no Leste Asiático e na Califórnia: uma perspectiva espacializada de Minsky. Economia e Sociedade. Campinas, n. 11, p. 73-136, dez. 1998.

FAZARI, L.; FERRI, P.; GREENBERG, E. Cash flow, investment, and Keynes-Minsky cycles. Journal of Economic Behavior \& Organization. Tennessee, n. 3, v. 65, p. 555-572, mar. 2008. 
FISHER, E.; BERNARDO, J. L. The Political Economy of Shadow Banking: Debt, Finance and Distributive Politics under a Kalecki-Goodwin-Minsky SFC Framework. New York: Levy Economic Institute. May 2014 (Working Paper, n. 801).

FUJITA, S.; SASAKI, H. Financialization and its Long-run Macroeconomic Effects in a Kalecki-Misky Model. Kyoto: Kyoto University. April 2011 (Working Paper, n. E-11-oo1).

GODLEY, W.; M. LAVOIE. Fiscal Policy in a Stock-Flow Consistent (SFC) Model. In: The Stock-flow Consistent Approach: Selected Writings of Wynne Godley, eds. LAVOIE, M.; ZEZZA, G. p. 194-215. New York: Palgrave Macmillan. [2007] 2012.

HANNSGEN, G.; YOUNG-TAFT, T. Inside Money in a Kaldor-Kalecki-Steindl Fiscal Policy Model: The Unit of Account, Inflation, Leverage, and Financial Fragility. New York: Levy Economic Institute. June 2015 (Working Paper, n. 839).

HEWITSON, G. Post-Keynesian monetary theory: some issues. Journal of Economic Surveys. Hamilton, n. 9, v. 3, p. 285-310, set. 1995.

KALECKI, M. A. Theory of the Business Cycle. The Review of Economic Studies. Stockholm. vol. 4. n. 2. p. 77-97, fev. 1937 a.

KALECKI, M. A. Theory of Economic Dynamics: An Essay on Cyclical and Long-Run Changes in Capitalist Economy. London: George Allen and Unwin, 1954.

KALECKI, M. A. The Principle of Increasing Risk. Economica (New Series). Melbourne, v. 4, n. 16, p. 440-447, nov. 1937 b.

KALECKI, M. A. The determinants of distribution of the national income. Econométrica. Massachussetts, n.6, v. 2, p. 97-112, abr. 1938.

KALECKI, M. A. Teoria da Dinâmica Econômica. Ensaio sobre as mudanças cíclicas e a longo prazo da economia capitalista. São Paulo: Abril S.A Cultural e Industrial, 1983.

KEYNES, J. M. (1936). Teoria Geral do Emprego, do Juro e da Moeda. São Paulo: Abril Cultural (Coleção Os Economistas), 1983.

LABINI, P. S. Oligopólio e Progresso Técnico. Forense: Rio de Janeiro, 1984.

LAVOIE, M. Horizontalism, structuralism, liquidity preference and the principle of increasing risk. Scottish Journal of Political Economy. Scotland. v. 43, n. 3, p. 275-300, ago. 1996. 
LAVOIE, M.; M. SECCARECCIA. Minsky's financial Fragility Hypothesis: A Missing Macroeconomic Link? In FERRI, P.; BELLOFIORE, R. (Eds.). Financial Fragility and Investment in the Capitalist Economy: The Economic Legacy of Hyman Minsky. V. II. Cheltenham: Edward Elgar, 2001. DOI: https://doi.org/10.4337/9781781009758.00012

MINSKY, H. P. Estabilizando uma economia instável. São Paulo: Novo Século, 2010.

MINSKY, H. P. John Maynard Keynes. Campinas: Editora da Unicamp, 2011.

MINSKY, H. P. Longer Waves in Financial Relations: Financial Factors in the More Severe Depressions. The American Economic Review, Petesburgo. vol. 54. n. 3. p. 324-335, mai. 1964 .

MINSKY, H. P. The Relevance of Kalecki: The Useable Contribution. PSL Quarterly Review. Roma. vol. 67. n. 265. p. 95-106. set. 2013.

MOTT, T. Kalecki's principle of increasing risk, the distribution of income, and consequences for macroeconomic performance. In: SADOWSK, Z. L.; SZEWORSKI, A. Kalecki's Economics Today. Londres: Routledge, 2004. p. 79-86.

NELSON, R. R. What enables rapid economic progress: what are the needed institutions? Research Policy. North Carolina. v. 37. n. 1. p. 1-11. Fev. 2008. DOI: https://doi.org/10.1016/j.respol.2007.10.008

POSSAS, M. L. Demanda Efetiva, Investimento e Dinâmica: A atualidade de Kalecki para a teoria macroeconômica. In: POMERANZ, L. et al (Org). Dinâmica Econômica do Capitalismo Contemporâneo: Homenagem a M. Kalecki. São Paulo: Editora da USP, 2001. p. 99-126.

RONCAGLIA, A. Hyman Minsky's monetary production economy. PSL Quarterly Review. Roma, v. 66, n. 265, p. 77-94, jul. 2013. DOI: https://doi.org/10.2139/ssrn.3136991

RONCAGLIA, A. Macroeconomics in crisis and macroeconomics in recovery. PSL Quartely Review. Roma, v. 64, n. 257, p. 167-185, mai. 2011.

STEINDL J. Maturity and stagnation in American capitalism, Oxford: Basil Blackwell, 1952.

STEINDL J. Economic papers 1941-88. London: Macmillan, 1990.

TAPIA, J. A. Money and Say's law: on the macroeconomic models of Kalecki, Keen, and Marx, Real-World Economics Review, n. 70, p. 110-120, feb. 2015. 
TEIXEIRA, A. M.; MISSIO, F. J. O "novo" consenso macroeconômico e alguns insights da crítica heterodoxa. Economia e Sociedade. Campinas, v. 20, n. 2(42), p. 237-297, ago. 2011.

TOPOROWSKI, J. The Monetary Theory of Kalecki and Misnky. London: Department of Economics School of Oriental and African Studies, mar. 2012. (Working Paper, n. 172). DOI: https://doi.org/10.1093/cje/bemo59

TOPOROWSKI, J. Minsky's 'Induced Investiment and Business Cycles'. Cambridge Journal Economics, v. 32, p. 725-737, feb. 2008.

TYMOIGNE, E. The Minskyan System, Part II: Dynamics of the Minskyan Analysis and the Financial Fragility Hypothesis. The Levy Economics Institute. New York: Working Paper. n. 453 , jun. 2006. 